\title{
Long-term safety and efficacy of nevirapine (NVP)-based antiretroviral therapies
}

\author{
F Rodriguez-Arrondo*1, K Aguirrebengoa ${ }^{2}$, J Portu ${ }^{3}$, J Muñoz ${ }^{4}$, MA Garcia ${ }^{5}$, \\ J Goikoetxea ${ }^{2}$, E Martinez ${ }^{5}$, JA Iribarren ${ }^{1}, \mathrm{~N} \mathrm{Perez}^{6}, \mathrm{C} \mathrm{Alcarez}^{6}$ and B Clotet ${ }^{6}$
}

Address: ${ }^{1}$ Hospital Donostia, San Sebastian, Spain, ${ }^{2}$ Hospital de Cruces, Bilbao, Spain, ${ }^{3}$ Hospital Txagorritxu, Vitoria, Spain, ${ }^{4}$ Hospital Basurto, Bilbao, Spain, ${ }^{5}$ Hospital Galdakoa, Bilbao, Spain and ${ }^{6}$ Fundacio Lluita contra la SIDA i IrisCaixa, Badalona, Spain

* Corresponding author

from Ninth International Congress on Drug Therapy in HIV Infection

Glasgow, UK. 9-13 November 2008

Published: 10 November 2008

Journal of the International AIDS Society 2008, I I (SuppI I):P33 doi:I0.I I86/I758-2652-II-SI-P33

This abstract is available from: http://www.jiasociety.org/content/II/SI/P33

(C) 2008 Rodriguez-Arrondo et al; licensee BioMed Central Ltd.

\section{Purpose of the study}

The presentation will report long-term ( $>4$-year) data on safety and efficacy of antiretroviral regimes including NVP as a component of their antiretroviral therapy in five centers' databases, and included in a retrospective cohort study.

\section{Methods}

Data collected included lipid and liver function tests, viral load and CD4 cell counts at baseline, 2-year and >4-year timepoints. HCV co-infection, adverse events, and reason for using NVP were also recorded.

\section{Summary of results}

229 patients (pts) were included. Mean age was 37 years. Most pts (54\%) were former intravenous drug users. 135 individuals were co-infected with HCV. Median time on NVP was 72.6 months. The main reasons to use NVP were: second or third-line therapy (40\%), simplification (30\%), first-line therapy (19\%), and efavirenz intolerance (10\%). Combinations of nucleosides most widely used were: $\mathrm{ABC}+3 \mathrm{TC}(25 \%), \mathrm{AZT}+3 \mathrm{TC}(23 \%)$ and TDF+3TC (14\%). HDL-cholesterol and GGT increased from baseline to $>4$ year timepoint $(48 \mathrm{mg} / \mathrm{dl}$ to $62 \mathrm{mg} / \mathrm{dl}$ and $58 \mathrm{U} / \mathrm{l}$ to 145 $\mathrm{U} / \mathrm{l}$, respectively). LDL-cholesterol, triglycerides and alkaline phosphatase showed decreasing values at follow-up $(135 \mathrm{mg} / \mathrm{dl}$ to $109 \mathrm{mg} / \mathrm{dl}, 216$ to $153 \mathrm{mg} / \mathrm{dl}$, and 177 to 92 , respectively). Total cholesterol and liver function tests had no significant changes. CD4 cell counts increased from $439 / \mathrm{mm} 3$ at baseline to $628 / \mathrm{mm} 3$ at the last available visit. 172 out of 184 pts who remained on NVP-based therapy at last visit maintained viral load values below limit of detection. NVP was stopped or withdrawn in 43 patients due to virological failure (13 pts), toxicity (five pts), virological resistance (four pts), therapy interruption (three pts), death (two pts), dyslipidemia (one pt), simplification (one pt) or unknown reasons (14 pts). Adverse events were reported in 40 patients but none was directly attributed to NVP. The reported follow-up pattern of laboratory tests was also found in the subset of HCV coinfected patients by comparing men and women and stratifying patients with a CD4 cell count cut-off value of 250/mm3.

\section{Conclusion}

Results suggest that NVP-based antiretroviral therapy (either first-line, simplification, or second-line) not only provides stable immunological and virological efficacy for over 4 years, as well as a favourable safety profile with few adverse events leading to discontinuation, but also increases HDL-cholesterol, which may have a protective impact on cardiovascular risk. The same safety profile was found in the subpopulation of HCV co-infected patients and individuals with CD4 cell counts above 250/mm3. 